\title{
SEMI-IDEAL BIDDING VIA A FUZZY TOPSIS PROJECT EVALUATION FRAMEWORK IN RISKY ENVIRONMENTS
}

\author{
Mehdi RAVANSHADNIA, Hossein RAJAIE \\ Construction Engineering and Management Group, Faculty of Engineering, \\ Islamic Azad University-Science and Research Branch-Tehran, Tehran, Iran \\ Received 31 Jul 2011; accepted 03 Apr 2012
}

\begin{abstract}
Blind involvement in aimless bids may result the loss of bidding bond expenditures, purchased bidding documents, the cost of human resources engaged in mark-up estimation, and detailed project investigation costs such as site visits. In this research, a risk based fuzzy TOPSIS framework is set up to evaluate and prioritize bidding opportunities. This may help contractors to assign their limited resources to near optimal selected projects. The risks inherent in the nature of every tender, makes systematic risk analysis a prerequisite for any construction company. Proposed framework considers key determining risk factors such as corporate considerations, tender environment, contractual issues, and project specific risks. The methodology implementation has been facilitated by developing a graphical user interface that accepts linguistic terms expressed by main decision groups. A case study demonstrates the applicability of the model.
\end{abstract}

Keywords: risk, bid/no-bid, decision making, fuzzy TOPSIS, contractor.

Reference to this paper should be made as follows: Ravanshadnia, M.; Rajaie, H. 2013. Semi-ideal bidding via a fuzzy TOPSIS project evaluation framework in risky environments, Journal of Civil Engineering and Management 19(Supplement 1): S106-S115. http://dx.doi.org/10.3846/13923730.2013.801884

\section{Introduction}

Multi-Criteria Decision Making (MCDM) has been one of the fastest growing areas during the last decades (Jahanshahloo et al. 2006). MCDM consists of MADM and MODM methods. MADM is the most well-known branch of decision making. It is a branch of a general class of operations research models that deal with decision problems under the presence of a number of decision criteria (Kahraman 2008). There are various categorizations of MADM methods that TOPSIS is one of the practical wide used ones.

Technique for Order Performance by Similarity to Ideal Solution (TOPSIS) is one of the most popular MADM methods. The philosophy behind the technique is to choose an alternative that is the nearest to the positive ideal solution and the farthest from the negative ideal solution. To model the problems more realistically, the diffusion of fuzzy sets into TOPSIS has been developed and applied recently.

This paper attempts to present a model that applies fuzzy TOPSIS model to help a contractor decide whether to bid or not to bid considering the risks of a tender. However, bidding strategy researches stems from works started in 1960s, but most of the proposed methods were not attended by practitioners.

Particularly these days with the global recession, contractors are facing more pressure of the market competition. This fact may lead them to bid in more tenders and propose lower bid prices. This makes bid/no-bid a critical decision, because a simple mistake may end in the bankruptcy of the corporate. Therefore, the application of a systematic bid/no-bid decision making may seem more necessary than ever in the practitioners' point of view.

This paper applies fuzzy TOPSIS to make appropriate decision when a contractor encounters a number of new projects for bidding. This paper focuses on the risk criteria exist in the project selection process.

\section{Literature review}

Technique for order performance by similarity to ideal solution (TOPSIS) was first developed by Hwang and Yoon for solving a MCDM problem (Hwang, Yoon 1981). Since then, many researchers developed or applied the technique. This survey categorized the recent works in theory development and application researches. Then, it surveys the academic works on risk management in bidding decisions.

\section{a) TOPSIS theory development}

According to the concept of the TOPSIS, a closeness coefficient is defined to determine the ranking order of all alternatives by calculating the distances to both the fuzzy positive-ideal solution (FPIS) and fuzzy negativeideal solution (FNIS) simultaneously by Chen (2000).

Olsson reviews several applications of TOPSIS using different weighting schemes and different distance 
metrics, and compares results of different sets of weights applied to a previously used set of multiple criteria data. TOPSIS was not found to be more accurate, but was quite close in accuracy (Olsson 2008). Also, TOPSIS has been developed for solving large scale multiple objective programming problems involving fuzzy parameters. The alpha-Pareto optimality is introduced by extending the ordinary Pareto optimality on the basis of the alpha level sets of fuzzy numbers (Abo-Sinna, Abo-El-Enien 2006). Jahanshahloo et al. (2006) extended the TOPSIS method to decision-making problems with fuzzy data. They expressed the rating of each alternative and the weight of each criterion in triangular fuzzy numbers. The normalized fuzzy numbers is calculated by using the concept of alpha-cuts (Jahanshahloo 2006). Wang and Elhag proposed a fuzzy TOPSIS method based on alpha level sets and presents a nonlinear programming (NLP) solution procedure. The relationship between the fuzzy TOPSIS method and fuzzy weighted average (FWA) is also discussed in their paper (Wang, Elhag 2006). Kahraman presented a comparison of fuzzy TOPSIS methods based on their attribute weights, type of fuzzy numbers, ranking method, and normalization method (Kahraman 2008).

\section{b) TOPSIS applications}

TOPSIS and fuzzy TOPSIS have been applied in various fields recently. Material selection (Jee, Kang 2000), plant location selection (Chu 2002), robot selection (Chu, Lin 2003), the evaluation of land use planning project (Tang et al. 2005), evaluation of hospital performance (Fang, Zhang 2005), facility location (Ertuğrul, Karakaşoğlu 2008), supplier selection (Wang et al. 2009), and performance evaluation of cement firms (Ertuğrul, Karakaşoğlu 2009) are some of the applications. One of the relevant works that applies TOPSIS in bidding was developed by Li and Xie (2006). They build a scientific evaluation TOPSIS model to evaluate bidding in the manufacturing enterprises. The result shows TOPSIS is a good method in the manufacture enterprise invitation and submission of bids, and has great practical value $(\mathrm{Li}, \mathrm{Xie}$ 2006). Mahmoodzadeh et al. (2007) developed a project selection methodology based on AHP and fuzzy TOPSIS approach. By utilizing improved Analytical Hierarchy Process by Fuzzy set theory, first they tried to calculate weight of each criterion. Then by implementing TOPSIS algorithm, assessment of projects has been done (Mahmoodzadeh et al. 2007).

\section{c) Risk management in bid/no-bid decisions}

Moselhi and Deb (1993) presented a simple methodology for the selection of a project under risk. The method considers multi-objective decision criteria and takes into account the uncertainties associated with each individual objective (Moselhi, Deb 1993). Minato and Ashley (1998) postulated that there exist some co variable risks, or corporate risk, among a company's project portfolio, and maintained that such risks could be diminished efficiently using strategies made at the higher levels of corporate management rather than strategies at the project level. They proposed a risk analysis framework from company's point of view (Minato, Ashley 1998). Baker et al. (1998) surveyed risk analysis techniques employed by the companies. They concluded that personal and corporate experience and engineering judgment are the most successful qualitative techniques; scenario analysis, EMV, ENPV, and break-even analysis being the principal quantitative techniques (Baker et al. 1998). Ye and Tiong (2000) developed the net-present-value-at-risk (NPV-atrisk) method to decide to invest in privately financed infrastructure projects or not. They have considered two power projects for their model validation. Their research showed the method can be used in decision making for privately financed infrastructure projects. But, the decision makers should keep in mind that a major requirement in using the NPV-at-risk method is the availability of data for statistical analysis and the reliability of NPV-at-risk depends on the simulation results derived from the specified distributions and cash flow models. Also, its ability to deal with risk also depends on the quality of the simulation model (Ye, Tiong 2000). Carr and Tah (2001) described a hierarchical risk breakdown structure is described to represent a formal model for qualitative risk assessment. They used fuzzy approximation to identify and quantify the relationships between risk sources and consequences (Carr, Tah 2001). Zeng et al. (2007) used a modified analytical hierarchy process to structure and prioritize diverse risk factors. They applied fuzzy reasoning techniques to handle the uncertainties and subjectivities arising in the construction process (Zeng et al. 2007).

Han et al. (2004) focused on a financial portfolio risk management for international projects to integrate the risk hierarchy of both individual projects and at the corporate level, which applies a multi-criteria decision making method to maximize the total value of firms. Han et al. (2005), Han and Diekmann (2001) described findings from experiments done to investigate the risk attitude and bid decision behaviour in the selection of international projects. Olsson (2008) attempted to identify differences in managing a single project compared with that of a project portfolio and suggested a methodology to analyse project portfolio risks. In 2010, other researchers developed a model that helps contractors in selecting the most appropriate candidate projects for bidding considering their diversification policy. They included risk criteria as one of the five categories of important project portfolio selection criteria. The paper used a fuzzy simple additive weighting method for each project appraisal and received promising feedback from practitioners (Ravanshadnia et al. 2010).

\section{Basics of fuzzy TOPSIS}

Following, a brief description of basic definitions of fuzzy sets and TOPSIS theory is stated.

Definition 1 (fuzzy set): A fuzzy set $\tilde{a}$ in the universe of discourse $X$ is characterized by a membership function $\mu_{\tilde{a}}(x)$ which associates with each element $x$ in $X$, a real number in interval $[0,1]$. The function value $\mu_{\tilde{a}}(x)$ is termed the grade of membership of $x$ in $\tilde{a}$. 
Definition 2 (fuzzy number): A fuzzy number is a fuzzy subset of the universe of discourse $X$ that is both convex and normal. The triangular fuzzy numbers can be denoted as $\tilde{A}=\left(a_{1}, a_{2}, a_{3}\right)$ where $a_{2}$ is the central value $\left(\mu_{\hat{a}}(x)=1\right), a_{1}$ is the left spread and $a_{3}$ is the right spread (Fig. 1). It's a conceptual schema and mathematical form shown by Eqn (1):

$$
\mu_{\tilde{a}}(x)=\left\{\begin{array}{lr}
0 & x \leq a_{1} \\
\frac{x-a_{1}}{a_{2}-a_{1}} & a_{1}<x \leq a_{2} \\
\frac{a_{3}-x}{a_{3}-a_{2}} & a_{2}<x \leq a_{3} \\
0 & a_{3}<x
\end{array} .\right.
$$

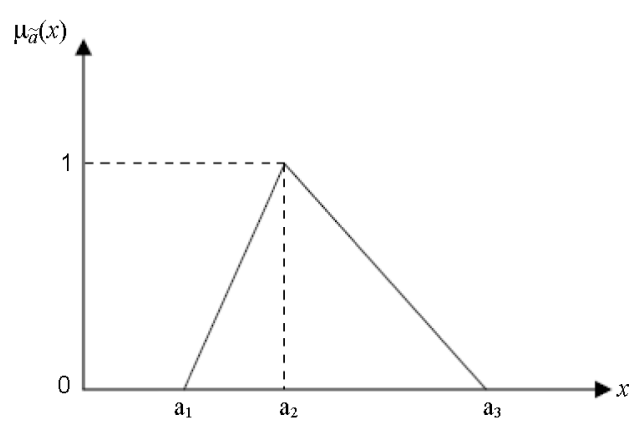

Fig. 1. A triangular fuzzy number

Definition 3 (linguistic variable): A linguistic variable is a variable which is expressed in linguistic terms. The concept of a linguistic variable is very useful to describe the situation that is too complex or has vagueness.

Definition 4 ( $\alpha$-cut): For exhibiting an element $x \in$ $X$ that typically belongs to a fuzzy set $\tilde{a}$ we may demand its membership value to be greater than some threshold $\alpha \in[0,1]$. The ordinary set of such element is the $\alpha$-cut $\tilde{a}$ of $\tilde{a}, \tilde{a}=\left\{x \in X, \mu_{\tilde{a}}(x) \geq \alpha\right\}$.

Definition 5 (multiplication of triangular fuzzy numbers): Suppose that we have two triangular fuzzy numbers $\tilde{A}=(a, b, c)$ and $\tilde{B}=(d, e, f)$, then, the multiplication of the fuzzy numbers $\tilde{A}$ and $\tilde{B}$ based on $\alpha$-cut approach if two fuzzy numbers were been positive, is defined as follows:

$$
\begin{gathered}
\tilde{A}^{\alpha}=\left[a_{L}^{\alpha}, a_{R}^{\alpha}\right] ; \\
\tilde{B}^{\alpha}=\left[b_{L}^{\alpha}, b_{R}^{\alpha}\right] ; \\
(\tilde{A} \cdot \tilde{B})=\left[\left(a_{L}^{\alpha} \cdot b_{L}^{\alpha}\right),\left(a_{R}^{\alpha} \cdot b_{R}^{\alpha}\right)\right] .
\end{gathered}
$$

Definition 6 (the distance between two fuzzy numbers): Let $\tilde{A}=\left(a_{1}, a_{2}, a_{3}\right)$ and $\tilde{N}=\left(n_{1}, n_{2}, n_{3}\right)$ be two triangular fuzzy numbers, then the distance between them using vertex method is defined as:

$$
\left.d(\tilde{A}, \tilde{N})=\sqrt{\frac{1}{3}\left[\left(a_{1}-n_{1}\right)^{2}+\left(a_{2}-n_{2}\right)^{2}+\left(a_{3}-n_{3}\right)^{2}\right.}\right] .
$$

\section{Risk Based fuzzy TOPSIS bid/no-bid model}

TOPSIS is a multiple criteria method to identify solutions from a finite set of alternatives. A systematic fuzzy TOPSIS approach was extended in this section to extract index of each project with fuzzy TOPSIS.

Proposed model extracts weights from expert's view stated in fuzzy linguistic terms, accepts the values of each attributes in linguistic terms, translates the linguistic terms into fuzzy membership functions, and then applies defuzzification process for extracting final crisp weights of every criterion. Then, fuzzy TOPSIS methodology is used to define utility function. Finally, evaluated projects are ranked by their indices. To implement the model, a software program was developed in the form of a graphical user interface in MATLAB 7.1. The graphical user interface consists of different toolboxes that makes possible to insert the experts' judgments regarding the attributes, every project's evaluation with respect to each attribute, and final project ranking. It is possible to enter criteria weights, and to express the value of each project with respect to every criterion in linguistic terms. The software facilitates mathematical operations and encourages decision makers to apply the model in practical cases. The procedure for making bid/no-bid decisions based on the mentioned model consists of the following steps:

\section{Step 1. Establishing risk based bid evaluation criteria}

A bidding committee would develop the risk based bidding decision making criteria. A bidding committee can include company manager, project managers, operation group, technical group, HSE group, etc. As mentioned in the case study, the current research developed 15 attributes in 5 categories that each criterion consists of 3 sub-criteria. Here, by "attribute" the text means general meaning of decision making attribute, but the words "criterion" and "sub-criterion" are used when the attributes are used in hierarchical order. The model decomposes the decision criteria into a hierarchy of more easily comprehended sub-criteria, each of which can be analysed independently by the experts. These criteria and sub-criteria were developed by a team of experts helping the model designing. The decision makers systematically evaluate the various sub-criteria with respect to their impact on an element above them in the hierarchy. The user of the software can give the normalized weights by writing them into corresponding text fields (Fig. 4).

\section{Step 2. Defining linguistic terms to fuzzy linguistic va- riables in membership function format}

There are several ways for deriving MFs like experimental data, perception of linguistic terms and the simulation of reality. Triangular, trapezoidal, S-shaped, Gaussian, Sigmoid curve membership functions are the most famous and applicable membership functions. In construction industry triangular and trapezoidal MFs are the most used. In this paper, triangular MFs for representing linguistic terms were used. Table 1 shows these variables. 


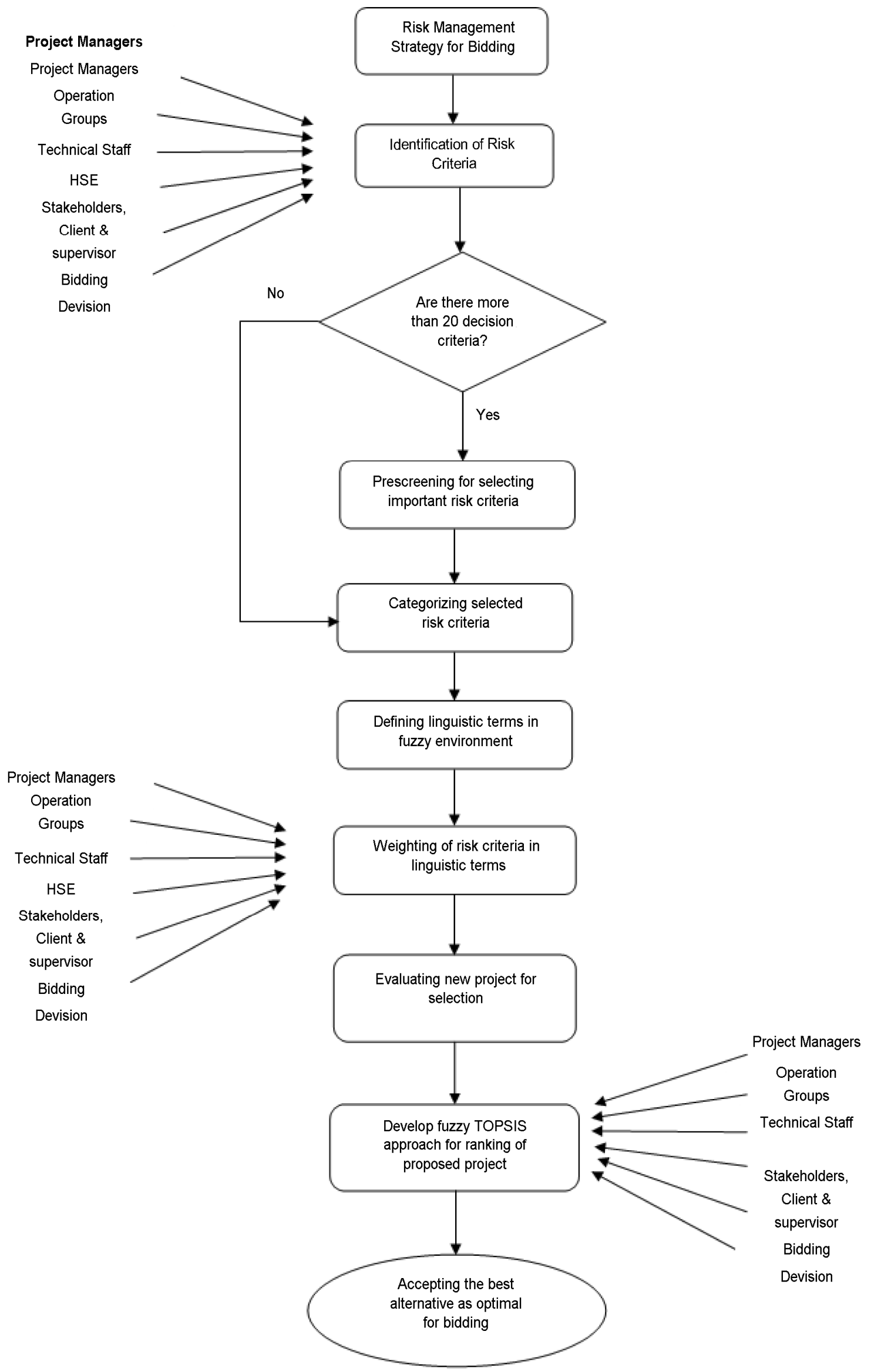

Fig. 2. Proposed methodology algorithm 
Table 1. Linguistic terms

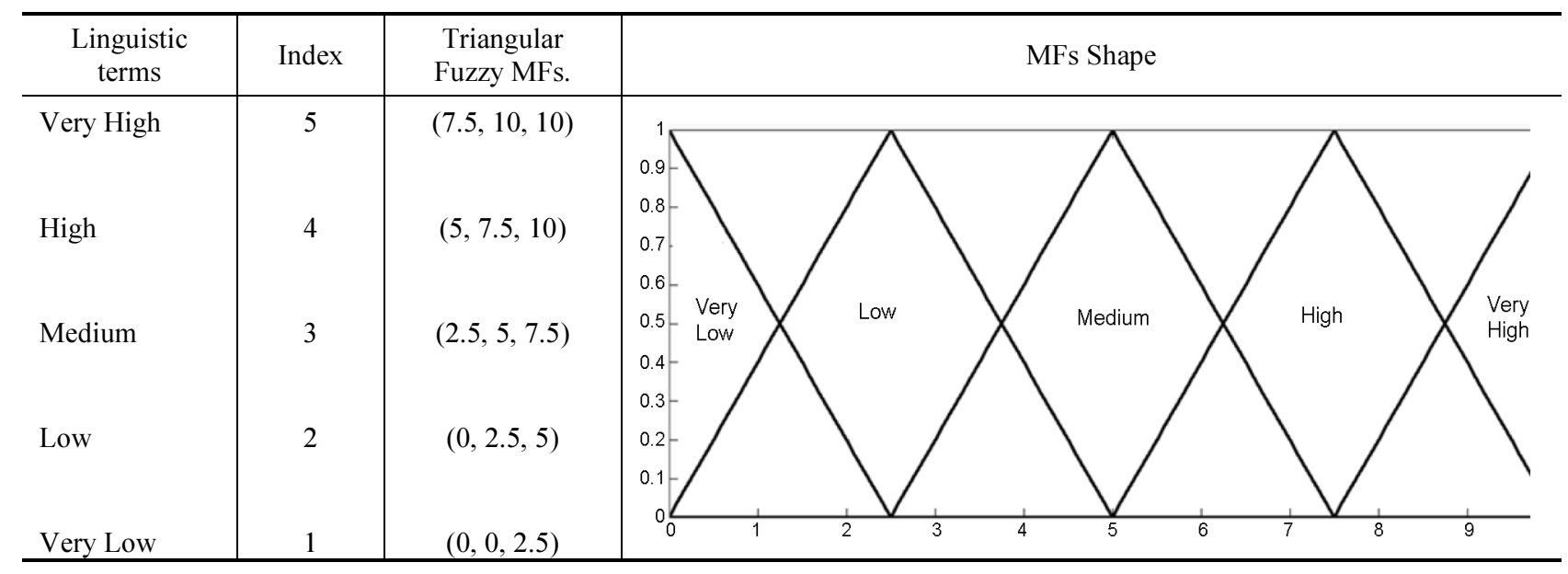

Step 3. Transforming group decisions on weights to a single fuzzy number

As the view points are expressed in a team, finalizing the weight would be done by deriving an average fuzzy number:

$$
\tilde{r}_{i j}^{m}=\frac{1}{k}\left(\tilde{r}_{i j}^{1}+\tilde{r}_{i j}^{2}+\tilde{r}_{i j}^{3}+\ldots+\tilde{r}_{i j}^{k}\right)
$$

where $\tilde{r}_{i j}^{k}$ are the rating weight of the $k^{\text {th }}$ decision maker.

Step 4. Inserting the importance of every attribute in linguistic term format

The experts of the construction company express their priorities regarding the criteria. They do this by selecting the words "very high", "high", "moderate", "low", "very low".

\section{Step 5. Calculating fuzzy attributes weights}

In this step, based on multiplication of two triangular fuzzy numbers, extracting $\tilde{r}_{i j}^{k}$ relevant to the each sub-criterion category multiplies in extracting $\tilde{r}_{i j}^{k}$ relevant to the each criterion.

\section{Step 6. Defuzzifying fuzzy MFs and extracting crisp weights}

Many researchers such as Lee and Li (1988), Dubios and Prade (1982), and Nakamura (1986) have contributions regarding the problem. One of the most applicable fuzzy ranking methods is the centroid index method. According to this method, geometric centre of each fuzzy number would be calculated to compare fuzzy numbers. Each geometric centre corresponds an $x$ value on the horizontal axis and a $y$ on the vertical axis. There are different ideas for using this method.

Geometric centre of $x$ value can be expressed as:

$$
\mathrm{x}_{0}=\frac{\sum_{\mathrm{x}_{\min }}^{\mathrm{x}_{\max }} \mathrm{xA}(\mathrm{x})}{\sum_{\mathrm{x}_{\min }}^{\mathrm{x}_{\max }} \mathrm{A}(\mathrm{x})},
$$

where: $x$ is a variable between minimum and maximum values; $A(x)$ is the membership function of fuzzy number.

\section{Step 7. Weights normalization}

In order to have a final normalized weight, a normalization process would be done based on the following equation:

$$
w_{i}=\frac{x_{i}}{\sum_{i=1}^{n} x_{i}},
$$

where: $x_{i}$ is defuzzified number of each $i^{\text {th }}$ attributes; $w_{i}$ is normalized weight of $i^{\text {th }}$ attributes. Step 8. Identifying existing projects for choosing approp-
riate projects

In this step, a management committee would search to select from proposed projects. They may omit projects from evaluation because they are out of the company's experience, they are very small, or they do not fit to the predefine company's strategies. Output of this step is a group of projects which the company might be eager to evaluate for bidding.

\section{Step 9. Develop fuzzy TOPSIS utility function}

9.1. Develop decision matrix: A fuzzy multi-criteria decision-making problem which can be concisely expressed in matrix format as:

$$
\tilde{E}=\left(\begin{array}{ccccc}
\tilde{e}_{11} & \tilde{e}_{12} & \tilde{e}_{13} & \ldots & \tilde{e}_{1 m} \\
\tilde{e}_{21} & \tilde{e}_{22} & \tilde{e}_{23} & \ldots & \tilde{e}_{2 m} \\
& & \cdot & & \\
& & \cdot & & \\
& & \cdot & & \\
\tilde{e}_{n 1} & \tilde{e}_{n 2} & \tilde{e}_{n 3} & \ldots & \tilde{e}_{n m}
\end{array}\right),
$$

where $\tilde{e}_{i j} ;$ for $i=1,2,3, \ldots, n, j=1,2,3, \ldots, m$ are linguistic variables. These linguistic variables can be described by triangular fuzzy numbers. 
9.2. Normalizing experts judgment: For decision matrix denoted by $\tilde{R}$ is shown as: $\tilde{R}=\left[\tilde{r}_{i j}\right]_{\mathrm{m}^{*} \mathrm{n}}$.

$$
\text { If }\left(\tilde{r}_{i j}, i=1,2, \ldots, m, j=1,2, \ldots, n\right) \text { are triangular }
$$

fuzzy number $\tilde{A}=\left(a_{1}, a_{2}, a_{3}\right)$, the normalization process can be demonstrate as below:

$$
\begin{gathered}
\tilde{r}_{i j}=\left(\frac{a_{1_{i j}}}{c_{j}^{+}}, \frac{a_{2_{i j}}}{c_{j}^{+}}, \frac{a_{3_{i j}}}{c_{j}^{+}}\right) \quad i=1,2, \ldots, m, j \in \tilde{A} ; \\
\tilde{r}_{i j}=\left(\frac{c_{j}^{-}}{a_{1_{i j}}}, \frac{c_{j}^{-}}{a_{2_{i j}}}, \frac{c_{j}^{-}}{a_{3_{i j}}}\right) \quad i=1,2, \ldots, m, j \in \tilde{A} ; \\
c_{j}^{+}=\max a_{3_{i j}} \quad j \in \tilde{A} ; \\
c_{j}^{-}=\min a_{1_{i j}} \quad j \in \tilde{\mathrm{A}} .
\end{gathered}
$$

The normalization method mentioned above is to preserve the property that the ranges of normalized triangular fuzzy numbers belong to $[0,1]$.

9.3. Developing weighted normalized matrix: A weighted normalized matrix is constructed to derive final utility function:

$$
\tilde{U}=\left[v_{i j}\right]=\left(\begin{array}{ccc}
\tilde{r}_{11} \cdot w_{1} & \tilde{r}_{12} \cdot w_{1} & \tilde{r}_{13} \cdot w_{1} \ldots \tilde{r}_{1 m} \cdot w_{1} \\
\tilde{r}_{21} \cdot w_{2} & \tilde{r}_{22} \cdot w_{2} & \tilde{r}_{23} \cdot w_{2} \ldots \tilde{r}_{2 m} \cdot w_{2} \\
& \cdot \\
& \cdot \\
& \cdot \\
\tilde{r}_{n 1} \cdot w_{n} & \tilde{r}_{n 2} \cdot w_{1} & \tilde{r}_{n 2} \cdot w_{1} \ldots \tilde{r}_{n m} \cdot w_{n}
\end{array}\right),
$$

where: $\tilde{r}_{i j}$ for $i=1,2,3, \ldots, n ; j=1,2,3 \ldots, m$, is normalized triangular fuzzy number that demonstrate rates of expert's evaluation about alternatives; $w_{i}$, for $i=1,2,3 \ldots$, $n$, is weight of attributes.

9.4. Identifying potential projects for weighting as alternatives for selection model: The projects which are in the market for tendering are identified, categorized and considered for further evaluation in the following steps.

9.5. Evaluating alternatives in terms of attributes: In this step, experts will state their priorities of alternatives regarding every attribute.

9.6. Determining Fuzzy Positive-Ideal Solution (FPIS) and Fuzzy Negative-Ideal Solution (FNIS): For determining FPIS and FNIS the following formula can be used:

$$
\begin{aligned}
A^{+}= & \left\{v_{1}^{+}, v_{2}^{+}, v_{3}^{+}, \ldots, v_{n}^{+}\right\}= \\
& \left\{\left(\max _{i} v_{i j} \mid j \in J_{1}\right),\left(\min _{i} v_{i j} \mid j \in J_{2}\right) \mid i=1,2, \ldots, n\right\} ; \\
A^{-}= & \left\{v_{1}^{-}, v_{2}^{-}, v_{3}^{-}, \ldots, v_{n}^{-}\right\}= \\
& \left\{\left(\min _{i} v_{i j} \mid j \in J_{1}\right),\left(\max _{i} v_{i j} \mid j \in J_{2}\right) \mid i=1,2, \ldots, n\right\},
\end{aligned}
$$

where: $J_{1}$ is the positive attributes; $J_{2}$ is the negative attributes.
9.7. Calculating the distance of alternatives from FPIS and FNIS: In this paper Vertex approach was applied for determining fuzzy distances. The calculations will be done based on Definition 6 .

9.8. Determining TOPSIS indices of every alternative: After determining TOPSIS utility function for each alternative, or after calculating the distance between each alternative from FPIS and FNIS ranking index of each project can be calculated:

$$
R i_{i}=\frac{d_{i}^{-}}{d_{i}^{-}+d_{i}^{+}}
$$

where: $R i_{i}$, for $i=1,2,3, \ldots, n$, is the ranking index of $i^{\text {th }}$ projects.

\section{Step10. Accepting the best alternative as "optimal" for bidding}

Based on the results of the previous step, the higher ranked project would be selected for bidding.

\section{Case study}

A large general contractor in the field of construction is selected for implementing the risk based fuzzy TOPSIS bid/no-bid model. Selected company has executed more than 200 projects with versatile natures over its 34 years experience. It has implemented $974 \mathrm{Kms}$ main paved roads and highways, $130 \mathrm{Kms}$ of railways, $850 \mathrm{Kms} \mathrm{sec-}$ ondary paved roads, infrastructure works and landscaping for 2 townships, more than 100 residential, commercial and industrial complexes, 8 tunnels, a large scale sewerage plant, and almost 130 mountain bridges so far.

The company has decided to expand its activities and establish its presence in new emerging markets. Having in mind the booming market in the region the company is eager to add new projects to its portfolio of projects. Therefore, it attempts to bid diversified tenders. In order to bid systematically based on the proposed fuzzy TOPSIS model ideal project and ideal bidding environment is defined by the company's main decision makers.

Ideal project: The ideal project for the company is a project that is in new geographical areas; the value of the project would preferably be between 45 to 60 million US\$; dam or metro projects are preferred; the lowest interrelation between the current project and new projects is desired; low resource intensive projects are held superior; mild weather conditions is an advantage; unit price construction projects are preferred; potentially high profit projects are brought before; projects within 15 to 30 months time scale are promoted in rankings.

Ideal bidding environment: The fewer number of bidders the better the tender is; a professional engineering company and highly qualified bidding documents is ideal; stable client regarding its payment and technical assessment procedures; unit price construction projects are preferred; stable economic condition and low inflation is desired; technically and financially well supported projects are preferred. 
Bidding Opportunities: There are three simultaneous projects in the market. A brief description of the potential projects is as follows:

Project No. 1 (Metro Project): A metro station construction project valued 22 million US\$, that is a part of Line 2 metro of one of the major central cities of Iran. The client has not implemented similar works before. The bidding documents are vague and not complete. The client is known for its on schedule payments. Time schedule to finish the project is 18 months. Working site is surrounded by highways and traffic considerations exist. The number of bidders is 9 qualified construction companies and tight competition is anticipated. The project contract is an EPC one with lump sum payment. The project needs new equipment (such as tower crane) which are not available in the company's current projects.

Project No. 2 (Dam Project): A rockfill dam construction project valued 56 million US\$. It is located in south west Iran. The client is has done similar works before, and the bidding documents are clear and complete. Payments are predicted to be delayed and therefore cash flow capability is required. The project contract is traditional and the contractor is being selected by supervisor. Payments are unit price based. Time schedule to finish the project is 36 months. The number of bidders is 4 construction companies.

Project No. 3 (Freeway Project): A $45 \mathrm{Kms}$ freeway valued almost 70 million US\$. It is located in a mountainous environment in west Iran. The client is a professional client in the field, and the bidding documents are clear and complete. Payments are predicted to be moderately delayed. The project contract is traditional and the contractor is being selected by supervisor. Payments are unit price based. Time schedule to finish the project is 28 months. The number of bidders is 6 qualified construction companies.

Fuzzy TOPSIS project selection considering risks. According to the mentioned methodology, corporation bidding committee identified project selection risks. After identifying risks of project selection, to extracting attribute weights 8 experts expressed their opinion about them. For extracting weight of each attribute DWA (Determining Weight of Attributes) software that is branch of PSCRM (Project Selection Considering Risk Management) package developed by authors. The expert's idea is imported in linguistic terms "Very High ( $\tilde{5})$ ", "High
(4) ", "Medium

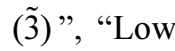
(2)", "Very Low
(i) " to

DWA software. DWA based on step 2 until step 7 calculating the attribute weights. However, the weight of each criterion is determined previously, it is possible to enter arbitrary weights in the software. Entering the opinions in linguistic terms is possible for practitioners as well. Fig. 3 presents the identified risks and their weights.

In order to implement the model, three practitioners of company were asked to apply the procedure. They were asked to evaluate risk of projects with respect to the 15 sub-criteria mentioned before. The ideas are imported in linguistic terms "Very High (VH)", "High (H)",
"Medium (M)","Low (L)", "Very Low(VL)" to PSCRM package. Finally PSCRM gives rank of evaluated projects based on declining risk. Project that qualified in grade 1 is risky than the other and so on.

Table 2 presents the ranking of three evaluated projects based on the introduced methodology:

Table 2. The final project ranking based on the model

\begin{tabular}{c|c|c|c}
\hline & The Name of Project & R Index & The Projects Rank \\
\hline 1 & Metro Project & 0.496 & 2 \\
\hline 2 & Dam Project & 0.726 & 1 \\
\hline 3 & Freeway Project & 0.181 & 3 \\
\hline
\end{tabular}

The user of the model uses the software entitled project selection considering risk management software (PSCRM) by entering each sub-criterion's weight and the value of every project with respect to every sub-criterion. The user can scroll down and select from "very high", "high", "medium", "low", and "very low". The software changes every linguistic term to a fuzzy number and use it in its fuzzy arithmetic. The software has the capacity to evaluate three projects simultaneously. The output of running the program is every projects final score which is described by R index (Fig. 4). Final projects evaluation results are illustrated in Table 2. It shows that the best project for bidding is the dam project. The second project is the metro project, and the worst is the freeway project. This helps the decision makers to systematically select the appropriate project for bidding.

\section{Conclusion}

There is no ideal project, therefore, key decision makers of construction companies should select a project which is the nearest to the ideal project for bidding. This research suggests a model that evaluates and ranks projects considering whether they are valuable for bidding or not.

A multi-stage decision making considering 15 attributes is used to determine whether to bid or not to bid. One of the major features of the research is focussing on the rule of risky attributes in project selection decision making.

Among multi-criteria decision making methods TOPSIS is used as a proven practical method. The developed model combines TOPSIS with the evolving discipline of fuzzy arithmetic which makes the model more applicable by adding the possibility of using linguistic terms. A software is designed to facilitate the decision making process.

The authors tested the proposed fuzzy TOPSIS model in a case study in a construction company. The key decision makers of the company described ideal bidding situation and ideal project, and evaluated the projects by using the model. Practitioners found the model applicable in the real case, especially when complex vague project selection decisions were mentioned.

It is highly recommended to test other MADM methods for the case and consider a comparison of the results in the future researches. Further, it can be valuable to test the model by using other influencing criteria such as companies' strategies or financial aspects. 


\section{Criteria}

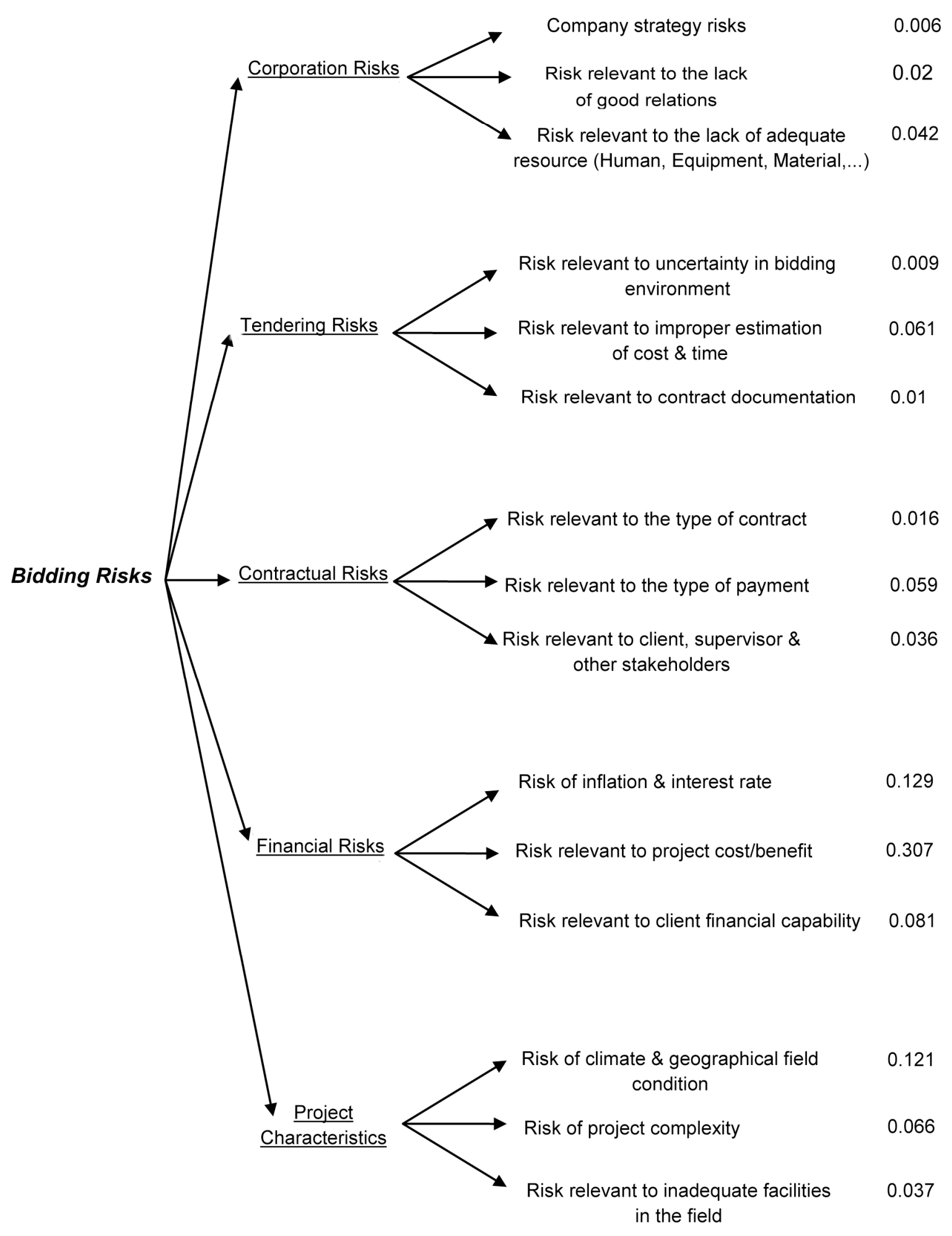

Fig. 3. Bidding risks categorization and weights 


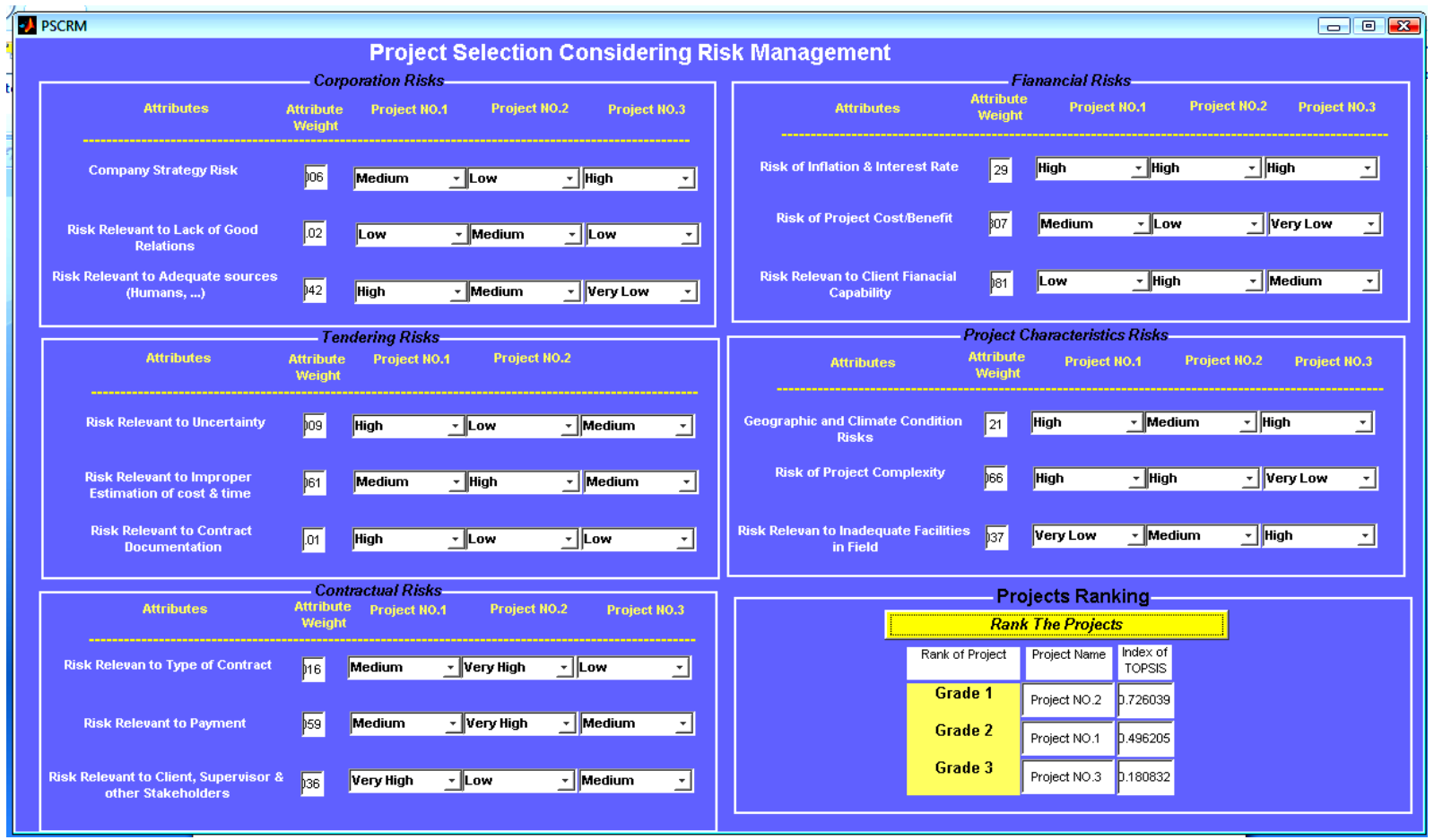

Fig. 4. A view of Project Selection Considering Risk Management (PSCRM) software

\section{References}

Abo-Sinna, M. A.; Abou-El-Enien, T. H. M. 2006. An interactive algorithm for large scale multiple objective programming problems with fuzzy parameters through TOPSIS approach, Applied Mathematics and Computation 177: 515-527. http://dx.doi.org/10.1016/j.amc.2005.11.030

Baker, S.; Ponniah, D.; Smith, S. 1998. Techniques for the analysis of risks in major projects, The Journal of the Operational Research Society 49(6): 567-572. http://dx.doi.org/10.2307/3010665

Carr, V.; Tah, J. H. M. 2001. A fuzzy approach to construction project risk assessment and analysis: construction project risk management system, Advances in Engineering Software 32: 847-857.

http://dx.doi.org/10.1016/S0965-9978(01)00036-9

Chen, C. T. 2000. Extension of the TOPSIS for group decisionmaking under fuzzy environment, Fuzzy Sets and Systems 114: 1-9. http://dx.doi.org/10.1016/S0165-0114(97)00377-1

Chu, T. C. 2002. Selecting plant location via a fuzzy TOPSIS approach, The International Journal of Advanced Manufacturing Technology 20: 859-864. http://dx.doi.org/10.1007/s001700200227

Chu, T. C.; Lin, Y. C. 2003. A fuzzy TOPSIS method for robot selection, The International Journal of Advanced Manufacturing Technology 21: 284-290. http://dx.doi.org/10.1007/s001700300033

Dubios, D.; Prade, H. 1982. A unifying view of comparison indices in a fuzzy set-theoretic framework, in Yager, R. R. (Ed.). Fuzzy set and Possibility Theory-Recent Development. New York: Pergamon Press. 13: 633.

Ertuğrul, I.; Karakasoğlu, N. 2008. Comparison of fuzzy AHP and fuzzy TOPSIS methods for facility location selection, The International Journal of Advanced Manufacturing Technology 39: 783-795.

http://dx.doi.org/10.1007/s00170-007-1249-8
Ertuğrul, I.; Karakaşoğlu, N. 2009. Performance evaluation of Turkish cement firms with fuzzy analytic hierarchy process and TOPSIS methods Elsevier, Expert Systems with Applications 36: 702-715.

http://dx.doi.org/10.1016/j.eswa.2007.10.014

Fang, S.; Zhang, Z. Y. 2005. Application of TOPSIS to the evaluation of hospital performance, Chinese Journal of Health Statistics 22(3): 169-170.

Han, S.; Diekmann, J. 2001. Approaches for making risk-based Go/No-Go decision for international projects, Journal of Construction Engineering and Management 127(4): 300308. http://dx.doi.org/10.1061/(ASCE)0733-9364(2001) $127: 4(300)$

Han, S.; Diekmann, J.; Lee, Y.; Ock, J. 2004. Multi-criteria financial portfolio risk management for international projects, Journal of Construction Engineering and Management 130(3): 346-356. http://dx.doi.org/10.1061/(ASCE) 0733-9364(2004)130:3(346)

Han, S.; Diekmann, J.; Ock, J. 2005. Contractor's risk attitudes in the selection of international construction projects, Journal of Construction Engineering and Management 131(3): 283-292. http://dx.doi.org/10.1061/(ASCE)07339364(2005)131:3(283)

Hwang, C.-L.; Yoon, K. 1981. Multiple-attribute decision making methods and applications, Lecture Notes in Economics and Mathematical Systems: 186. New York: Springer-Verlag. http://dx.doi.org/10.1007/978-3-642-48318-9

Ye, S.; Tiong, R. L. 2000. NPV-At-Risk method in infrastructure project investment evaluation, Journal of Construction Engineering and Management 126(3): 227-233. http://dx.doi.org/10.1061/(ASCE)0733-9364(2000)126: $3(227)$

Jahanshahloo, G. R.; Hosseinzadeh Lotfi, F.; Izadikhah, M. 2006. Extension of the TOPSIS method for decisionmaking problems with fuzzy data, Applied Mathematics and Computation 181: 1544-1551.

http://dx.doi.org/10.1016/j.amc.2006.02.057 
Jee, D.-H.; Kang, K.-J. 2000. A method for optimal material selection aided with decision making theory, Materials \& Design 99(21): 199-206. http://dx.doi.org/10.1016/S0261-3069(99)00066-7

Kahraman, C. 2008. Fuzzy multi-criteria decision making theory and applications with recent development. New York: Springer Science. 16: 591. http://dx.doi.org/10.1007/978-0-387-76813-7

Lee, E. S.; Li, R.-J. 1988. Comparison of fuzzy numbers based on the probability measure of fuzzy events, Computer and Mathematics with Applications 15(10): 887-897. http://dx.doi.org/10.1016/0898-1221(88)90124-1

Li, H.; Xie, Q. 2006. Application of TOPSIS in the bidding evaluation of manufacturing enterprises the algorithm of TOPSIS, in Proceedings of e-ENGDET2006 the $5^{\text {th }}$ International Conference on e-Engineering \& Digital Enterprise Technology, 16-18 August, 2006, Guiyang, China.

Mahmoodzadeh, S.; Shahrabi, J.; Pariazar, M.; Zaeri, M. S. 2007. Project selection by using fuzzy AHP and TOPSIS technique, International Journal of Human and Social Sciences 1(3): 135-141.

Minato, T.; Ashley, D. B. 1998. Data-driven analysis of "Corporate Risk" using historical cost-control data, Journal of Construction Engineering and Management 124(1): 4247. http://dx.doi.org/10.1061/(ASCE)0733-9364(1998) 124:1(42)

Moselhi, O.; Deb, B. 1993. Project selection considering risk, Construction Management and Economics 11(1): 45-52. http://dx.doi.org/10.1080/01446199300000063
Nakamura, K. 1986. Preference relation on a set of fuzzy utilities as a basis for decision making, Fuzzy Sets and Systems 20(2): 147-162. http://dx.doi.org/10.1016/0165-0114 (86)90074-6

Olsson, R. 2008. Risk management in a multi-project environment: an approach to manage portfolio risks, International Journal of Quality \& Reliability Management 25(1): 6071. http://dx.doi.org/10.1108/02656710810843586

Ravanshadnia, M.; Rajaie, H.; Abbasian, H. R. 2010. Hybrid fuzzy MADM project-selection model for diversified construction companies, Canadian Journal of Civil Engineering 37(8): 1082-1093. http://dx.doi.org/10.1139/L10-048

Tang, J.; Zhao, X.; Shi, X. 2005. Application of ideal point method to the evaluation of land use planning project, Transactions of the CASE 21(2): 56-59.

Wang, Y. M.; Elhag, M. S. 2006. Fuzzy TOPSIS method based on alpha level sets with an application to bridge risk assessment, Expert Systems with Applications 31: 309-319. http://dx.doi.org/10.1016/j.eswa.2005.09.040

Wang, J.-W.; Cheng, C.-H.; Kun-Cheng, H. 2009. Fuzzy hierarchical TOPSIS for supplier selection, Applied Soft Computing 9: 377-386. http://dx.doi.org/10.1016/j.asoc.2008.04.014

Zeng, J.; An, M.; Smith, N. J. 2007. Application of a fuzzy based decision making methodology to construction project risk assessment, International Journal of Project Management 25(6): 589-600. http://dx.doi.org/10.1016/j.ijproman.2007.02.006

Mehdi RAVANSHADNIA. Dr, an Assistant Professor and the Dean of Construction Engineering and Management at I.A.U. Science and Research branch-Tehran; PhD in Civil Engineering from Amirkabir University of Technology. He is also the reviewer of reputable construction management journals, and has some books and several papers in English and Persian and the reference website of Iranian construction engineering and management addressed: www.ravanshadnia.com. His research area and contributions include bidding strategy, the application of decision making in construction industry, H.S.E., construction equipment management, value engineering, and project portfolio management.

Hossein RAJAIE. Dr, a Professor Emeritus in the Construction Engineering and Management group of Amirkabir University of Technology. His research interests include the field of construction material, pipeline projects, and bidding practices of construction contractors. 